\title{
Inclusive design and schools
}

Book or Report Section

Accepted Version

Porter, J. (2018) Inclusive design and schools. In: Tse, H. M., Daniels, H., Stables, A. and Cox, S. (eds.) Designing Schools for the Future of Schooling: Contemporary Visions for Education. Routledge, London. Available at http://centaur.reading.ac.uk/80777/

It is advisable to refer to the publisher's version if you intend to cite from the work. See Guidance on citing.

Publisher: Routledge

All outputs in CentAUR are protected by Intellectual Property Rights law, including copyright law. Copyright and IPR is retained by the creators or other copyright holders. Terms and conditions for use of this material are defined in the End User Agreement.

www.reading.ac.uk/centaur 


\section{CentAUR}

Central Archive at the University of Reading

Reading's research outputs online 


\section{Inclusive Design and Schools}

\section{Introduction}

How do we include diverse communities of learners and give them a sense of belonging? Evidence gathered by the Children's Society (2015) indicates how "children's happiness with their environment is related to their overall wellbeing", and, given that children spend more of their waking time in school than any other location it is not surprising that school design has been shown to exert an important effect on students' experience. CABE (2008) argued that decisions about the design, planning and management of places can enhance or restrict a sense of belonging. While every child has a right to be educated in a mainstream school (UNCRPD Art 24, 2008) not every school is appropriately designed to provide an inclusive environment for all students with a diversity of needs. There are increasing pressures on schools to be selective, rising numbers of pupils excluded, and for some children with special educational needs, no school place at all. The extent to which the design and practice of a school promotes a sense of connectedness also impacts on the workforce. Staff who are well networked with others respond well to the challenges of at risk and vulnerable students (Ortega et al., under review). A sense of connectedness is important in raising staff morale, recruiting and retaining teachers (Struyve et al., 2016). The ecology of the school, arising as it does through the interplay of design and practice, is a crucial feature of the establishment of safe stable settings in which both staff and students can thrive (Robinson et al., 2016).

This chapter will explore the drivers of inclusive design; the social model of disability that informed principles and values underlying inclusive design; and the legal framework that has shaped a compliance culture of policy-making. Little attention has been paid to the ways in which school design shapes and is shaped by the practices of inclusion. The focus of much research has been in relation to the impact on achievement using building performance measures such as light, ventilation, sound, and temperature (e.g. Williams et al. 2015). Progress can be harder to measure in those who find learning difficult but Barrett et al. (2015) found a differential impact of these aspects on children in primary schools with: SEN; eligibility for Free School Meals; and English as an Additional Language. Much less attention has been paid to aspects such as student engagement (Oliveas-Ortz et al., 2017) or to spaces within the school that students actually think are important (Hopland \& Nyhus, 2015). Research instead has tended to consider specific disability groups whose experiences can contradict each other, with less attention paid to students described as 'vulnerable' or 'at risk' who do not belong to specific disability groups. Research on the impact of the environment on children with special educational needs and disability (SEND) can be viewed alongside a review of guidance on school buildings which in the UK can be summed up as a shift from generic guidance, to disability specific, to none. Arguably if the design process is inclusive, this offsets the inadequacy of guidance. Newson, in the preface to a seminal book entitled "Environmental Design for Handicapped Children" by Singh Sandhu and HendriksJansen (1976) points to the importance of "creating a genuine working dialogue with everyone concerned.... Suggestions for innovation, however technically brilliant, will fail I their intended purpose unless they are made to harmonise with the social realities of the overall situation in which they are applied....."px. Inclusive design as a process has a long history of advocates.

This is a critical time for the school to be experienced as "a more flourishing, stimulating, creative and productive place" (Clements-Croome, 2017), brought about through innovative and creative engagement with design and its use in practice. Through examining the recommendations for inclusive design we can appreciate the extent to which these create better environments for all. The societal cost of poor school design has yet to be fully realised, meanwhile the cost of exclusion, in human and financial terms is high. It will be evidenced that inclusive design is not an optional add on- but the essence of good design. We start however by exploring the ways in which educational inclusion has been understood with particular reference to children with special educational needs and disability (SEND) to frame the types of organisation of provision and the variety of educational practices.

\section{Context for Inclusive Design}


The way in which we have viewed inclusive education has evolved considerably over the past 70 years. Operatti et al (2014) traces its routes to the 1948 United Nations Declaration of Human Rights which gave all children the right to education. It was not however until 1970 that this basic right was introduced for all children in England when those with severe and profound learning difficulties were brought into the education system, and in Northern Ireland not until 1983. Children with severe and profound learning difficulties were largely educated in segregated schools, although with some small pockets of inclusive provision. The Warnocke report in 1978 brought about a seed change in the ways in which special educational needs became to be understood as a continuum of need. This changed the focus from thinking mostly about the $2 \%$ of children with more significant needs, to recognizing the wider group some 1 in 6 (18\%) children who at some point time would experience difficulties in learning, and whose needs had been largely overlooked. The Warnocke report shifted the approach from one of categorizing children on the basis of medical impairments to one of identification based on educational need and provision. It also served to draw attention to three overlapping forms of integration; locational (where all children were educated on the same site); social integration (where all children participating in social events and opportunities); and functional (all children participating in an educational programme). The term integration continues to be used in some settings but it is important to note that at a global level a rather different set of values and assumptions were associated with the drive towards inclusion. This can be clearly evidenced in the seminal Salamanca Statement and Framework (UNESCO 1994), which sets out the view that mainstream schools are:

the most effective means of combating discriminatory attitudes, creating welcoming communities, building an inclusive society and achieving education for all; (UNESCO 1994 p. ix)

This view has been further strengthened through the recognition that inclusive education is a condition for the development of inclusive societies (UNESCO 2010).

We can start to chart a shift from simply seeing inclusive education as a right of the individual child to embrace its transformative potential for developing a just and fair society, thus broadening the focus to all marginalised groups. This value change underpins the distinction between the use of the word integration, where adaptations are made in response to an individual child, but where there is an expectation that they "fit in," to that of inclusion. The latter involves a re-structuring and re-organisation, a whole school approach to build a school that views individual differences positively, as opportunities rather than problems. There is much debate about how this might best be achieved for example through collaborative, enquiry based approaches to learning, rather than didactic whole class learning. Notably Dyson and Milward (2000) argue that one of the hallmarks of a highly inclusive school is their flexibility, so that children have the possibility of spending time in different learning environments, utilize a variety of approaches to organisation of learning (individual, group and whole class work) and use a variety of activities to engage children. As a result of these debates there are a range of ways in which mainstream schools are organised and respond to children with SEND including within class support, withdrawal for some lessons, separate classes or a resource base and children may or may not move flexibly between these.

Government policy expresses some ambivalence towards inclusion and may explain the continued variation in the organisation of provision. The 1997 Green Paper "Excellence for All Children" (DfE 1997) aligned the English education system with the sentiments expressed in the Salamanca Statement. It advocated the principle of inclusion and an extension of the capacity of mainstream schools to respond to the needs of all children. Some local authorities have embraced this with a gradual closure of special schools. However the focus in subsequent policies has incrementally retracted from this position. Thus the most recent Code of Practice on Special Educational Needs (DfE 2014) has remarkably little to say about equality and inclusion other than:

Schools support pupils with a wide range of SEN. They should regularly review and evaluate the breadth and impact of the support they offer or can access. P93

At an individual level some safeguards are in place as the Code also points to the duties of schools under the Equality Act 2010. Schools 
must make reasonable adjustments, including the provision of auxiliary aids and services for disabled children, to prevent them being put at a substantial disadvantage. These duties are anticipatory - they require thought to be given in advance to what disabled children and young people might require and what adjustments might need to be made to prevent that disadvantage. Schools also have wider duties to prevent discrimination, to promote equality of opportunity and to foster good relations. P93

It is this legal driver which appears to underpin much of what is current with respect of inclusive school design.

\section{The Influence of the Social Model}

The principles of inclusive design are heavily influenced by the social model of disability, which, as we have already seen in the field of education, moved the focus from an individuals' impairments to the problems caused by disabling environments, barriers and cultures, (Oliver 1983). The basic tenets as set out by Finkelstein (2001) were: "It is society that disables us and disabled people are an oppressed social group", and he continues "our society is constructed by people with capabilities for people with capabilities and it is this that makes people with impairments incapable of functioning". P2

These writers drew attention to the many discriminatory practices in society and their activism brought about important policy and legislative changes, both in the UK and America (Barnes 2011). The social model has spawned a series of debates and revealed the complexity of understanding the impact of an impairment and making appropriate responses to disability. In part this concerns an understanding of environmental barriers as more than physical impediments to access. Reeve (2012), for example, describes the ways in which inaccessible spaces impact on ones sense of self: "you are out of place, you are different... a reminder of the physicality of our bodies" p82, and above all that you are seen as different, and don't belong here. There is an inextricable link between societal attitudes and accessibility. This has been strengthened through recognition of the false duality in constructions of the disabled/non-disabled, that it obscures the diversity that lies within the group. While some disabled people enjoy good health others experience pain, fatigue, vertigo, some have conditions that are cyclical or progressive. Some conditions are invisible. Denial of the experience of impairment is disempowering (Shakespeare 2006) and the introduction of a biopsychosocial model has brought together individual aspects with wider environmental ones. The World Health Organisation, for example, uses a framework that charts the interaction between body functions and structures, activity and participation and environmental factors (WHO 2001). This promotes an understanding that any given medical condition can impact to different degrees on physical capabilities and of the ways in which barriers within the environment impact on the opportunities to participate in a variety of activities.

The social model also places an emphasis on policies and practices that promote participation and empowerment as witnessed by the "Nothing About Us without Us" movement. Stakeholder involvement is central to bringing about environmental and organisational transformations. As we have seen it is schools that are the focus of change rather than the individual child and they are best placed to identify the barriers to participation. The foregrounding of environmental barriers and the involvement of stakeholders can be identified to different degrees in the responses of architects and designers with parallel historical changes.

A number of different terms have been used to describe designs that reflect the needs of a wide range of users. These have different geographical origins were underpinned by different values and have evolved over time. Indeed the term inclusive design had an inauspicious start, the tern coined by Coleman (1994) for use in the UK in recognition "that disability is a universal experience" if we take a life-course view so that "taking account of this in the design process, products, services and environments can be improved for the majority of customers." Thus the concept was espoused as an "exciting gateway to product innovation," rather than driven by the desire for a fair and just society. A later paper by Clarkson and Coleman (2015) described the move "from margins to mainstream," from disability adaptations to mainstream design. In the U.S, the term universal design was coined by a working group of architects led by Robert Mace in 1997 with the formulation of a set of broad principles, initially a set of ten and subsequently refined into seven (Omerod \& Newton 2005) that would guide designers. 
Equitable Use

Flexibility in Use

Simple and Intuitive Use

Perceptible Information

Tolerance for Error

Low Physical Effort

Size and Space for Approach and Use

\section{Principles of Universal Design}

These 7 principles illustrate clearly the intention to provide barrier free designs through a general rather than specific disability approach. While this approach has many strengths it also has critics that see it fostering the notion that there can be a single solution that is universally acceptable, that ignores the complexity of accommodating a range of needs. Similar criticisms could be made about the use of the term Design-for-All favoured by members of the EU or of barrier-free design (Omerod \& Newton 2005). In fact Design for All as set out by the Stockholm statement is underpinned by a clear ideology: "Design for All is design for human diversity, social inclusion and equality" Moreover "it aims to enable all people to have equal opportunities to participate in every aspect of society." (EIDD 2004). Design for All therefore embodies many of the beliefs that underpin inclusive schooling. However debate and discussion amongst those advocating the use of the term inclusive design has one particular advantage, its emphasis on the process of design rather than what some have seen as the utopian end product. Heylighen and colleagues define inclusive design:

"as a way of designing, an approach to design; that it focuses on how design can address the themes like diversity, equality and social inclusion: that it strives towards the greatest possible application: and that the resulting design can be used by all people." Heylighen et al 2017 P509

They argue that inclusive design requires attention to the ways in which people interact and how they experience the designed environment. Not only is this definition highly compatible with the view of inclusion within mainstream schools as a process rather than an end-product, something to constantly strive towards, but it embodies the understanding of disability as an experience rather than an impairment of functioning. While it may prove to be an elusive ideal it has also encouraged debate and recognition across an international community (Barnes 2011). In the UK the term inclusive design appears a more favoured option, and a search through library data bases confirms it to be a more widely used term in the UK.

In summary inclusive design changes the focus from specialized adaptations that address the needs of specific groups to designs for mainstream that benefit all. It embodies attitudes of equity in opportunities for participation. It is not to be understood in relation to a fixed specification but is indicative of the process of design and indeed redesign in the light of changes to circumstances.

\section{Legal Drivers}

As we have already seen legislation has been a major force for recognizing the Rights of disabled people. As we turn to consider this in more detail we can recognize areas of potential conflict. In the UK The Disability Discrimination law (DDA 1995) provided a precise definition of disability: the presence of an impairment (or health condition) that has lasted for a year or more (or is likely to) and which has a substantial effect on daily life. Also covered in the definition are issues of mental health. Disability is the dynamic interaction between impairment and attitudinal and environmental barriers that hinders a person's full and effective participation in society on an equal basis with others. Consequently the same health condition can lead to quite different experiences, dependent on the social, and physical environment. For some both the onset and offset will be gradual reflecting the fluctuating nature of the impairment or health condition. For others there may be a cyclical element. Thus fluidity is indicative of the need for flexibility rather than static design solutions. In this respect the legal system is compatible with the principles of inclusive design. 
The Equality Act 2010 which replaced the DDA extended the requirement for schools and LAs to carry out accessibility planning for disabled pupils. The advice highlights increasing participation in the curriculum, improving the physical environment and making information accessible. It further addressed the duty to make reasonable adjustments, one that taxes both schools and providers; factors a school may consider when assessing the reasonableness of an adjustment may include the financial or other resources required for the adjustment, its effectiveness, its effect on other pupils, health and safety requirements. Equality Act 2010.

More globally Article 9 of the UN convention on the Rights of Persons with Disability enshrines the obligation for states to "ensure to persons with disabilities access, on an equal basis with others, to the physical environment" and for children "States Parties shall ensure an inclusive education system at all levels" in Article 24. The UK government holds a slightly ambivalent attitude towards this as revealed in the most recent ODI periodic review on the rights of disabled persons. "In England, staff working with disabled children and young people in mainstream schools must include them in all opportunities to participate with other young people, in line with SDG 4." (ODI 2017). On the one hand it holds the view that some children's needs are better met in specialist provision, but on the other hand retains the commitment to offering parents choice with respect to places in mainstream and special schools. Moreover the periodic review proudly reports on Building regulations, the goals of an inclusive accommodation and the work of building control bodies to inspect and ensure compliance.

There are therefore two key drivers that underpin inclusive design: a human rights argument and the notion of a fair and just/democratic society. One approach has been to safeguard individual needs through the notion of (specific) reasonable adjustments, the other to identify a set of (generic) universal principles. In the face of this it is perhaps unsurprising that policy documents harbour these conflicting positions.

\section{Current Provision and Children with SEN}

Having discussed the drivers of inclusive design, we turn now to consider current provision and the implications it has for developing a set of general inclusive design principles or a more specific set of requirements. As we have seen there is a continuum of special educational need and if we look at the definition we can start to identify some of the challenges for considering inclusive design as more than a set of principles. A broad definition of special educational needs means that children may be given an SEN label in some settings, but not in others, depending on the type of provision that is generally available :

"A child or young person has SEN if they have a learning difficulty or disability which calls for special educational provision to be made for him or her." P15 Code of Practice (2014).

Although there is remarkable stability in the overall percentage of children with SEN there is considerable variation between different geographical areas. Some $2.8 \%$ of children are recognized as having significant needs that require a formalization of their access to additional support in a written plan, an Education, Health and Care Plan (ECHP) and a further $11.6 \%$ referred to as SEN Support (DfE 2017). Taking the distinction made earlier between locational, social and a more extensive functional integration, which we might see as full inclusion, specific data on the type of inclusion of pupils in the UK are harder to find. The majority of children with SEN are in mainstream provision with $46 \%$ of those with an Education and Health Care plan being educated in special provision (either special school or a pupil referral unit) and just $1.34 \%$ of those termed SEN support. Figures for segregated provision have increased over the previous 10 years, with increasing numbers of children with SEN being excluded from mainstream school. We also know that there are an increasing number of pupils with SEN without a school place. An aptly named report from the Office of the Children's Commissioner in 2014, 'It might be best if you looked elsewhere', illustrates how, despite the Equality Act, some mainstream schools discourage parents of children with SEND from applying for a place in their school. With time mainstream schools appear to be less well equipped to provide for all children. Figures for 2017 reveal that $7.4 \%$ of state funded primary schools have units or resourced provision and $21.4 \%$ of secondary schools. (DfE 2017). 
The most common type of primary special educational need relates to cognition and learning with children with Moderate Learning Difficulties forming the largest group of pupils with special educational needs and the majority of those children will not have an EHCP. The second largest group are children with speech and language difficulties and the third are children with social emotional and behavioural difficulties. All three groups are more likely to be educated in mainstream schools without the safeguard of an ECHP. It is noticeable how little literature exists with respect to the impact of school design on these groups of pupils who form the majority of pupils with SEN. Table 2 sets out the numbers of pupils by primary need- although the reader should be aware that many children have a variety of needs.

\begin{tabular}{|l|l|l|l|}
\hline & $\begin{array}{l}\text { \% of Pupils } \\
\text { with SEN } \\
\text { Support }\end{array}$ & $\begin{array}{l}\text { \% of pupils with } \\
\text { EHCP Plans }\end{array}$ & $\begin{array}{l}\text { Total } \\
\text { Number } \\
\text { of Pupils }\end{array}$ \\
\hline Specific learning difficulties & 15.1 & 3.7 & 146,873 \\
\hline Moderate learning difficulties & 25.2 & 12.6 & 259,713 \\
\hline Severe learning difficulties & 0.4 & 12.9 & 32,338 \\
\hline $\begin{array}{l}\text { Profound and Multiple } \\
\text { learning difficulties }\end{array}$ & 0.1 & 4.4 & 10,981 \\
\hline $\begin{array}{l}\text { Social, Emotional \& Mental } \\
\text { Health Difficulties }\end{array}$ & 17.3 & 12.4 & 186,793 \\
\hline $\begin{array}{l}\text { Speech Language and } \\
\text { Communication Difficulties }\end{array}$ & 22.0 & 14.3 & 234,076 \\
\hline Hearing Impairment & 1.7 & 2.6 & 21,167 \\
\hline $\begin{array}{l}\text { Visual Impairment } \\
\text { Multi-Sensory Impairment }\end{array}$ & 0.9 & 1.4 & 11,889 \\
\hline Physical Difficulties & 0.2 & 0.3 & 2,719 \\
\hline Autistic Spectrum & 2.3 & 5.6 & 33,686 \\
\hline Other & 5.2 & 26.9 & 108,403 \\
\hline & 5.3 & 2.5 & 54,342 \\
\hline
\end{tabular}

Table 1 Numbers of Pupils with SEND by Primary Need

The percentage of pupils with a statement or EHC plan attending maintained special schools has seen a year on year increase since 2010 , rising from $38 \%$ of pupils with statements attending maintained special schools to $44 \%$ of pupils with statements or EHC plans 2017. There has been a similar increase with respect to independent special (increasing from 4.2\% to 5.8\%). There are 1,037 state-funded and non-maintained special schools in England. The most common approved provision type for special schools is Autistic Spectrum Disorder suggesting that this group in particular is not well provided for in mainstream settings. The average size of special schools is around 110 pupils, half the average size of a primary school. Additionally there are around 350 pupil referral units, with an average size of 45 pupils.

\section{Impact of Environment on Children with SEND}

There is limited robust empirical data on the impact of the built school environment that is specific to children with SEND, and a tendancy for evaluators and researchers to draw (only) on the views of teachers and other adults. Observational data is largely lacking. One of the few studies to examine the impact of the environment on pupil progress and include an analysis of children with SEN was that of Barrett et al (2015)'s study of primary schools and 
they cautiously suggest that they were more sensitive to colour and sound. If we take this study as an exception, we can argue that our understanding of the effect of different aspects of school design on children with SEND is largely one of inference.

Wheeler \& Malekzadeh (2015) describe a number of common problems that can be found in new schools, and we can consider the differential impact on children with SEND. Their findings include poor acoustics, which will impact on the attention and engagement of children with a mild or intermittent hearing loss; lighting that is inefficient or performs poorly in classrooms, hall and corridors; again which will impact on both the learning and interaction of children with poor eyesight; poor air quality and temperature control which will have a differential impact on the (growing) numbers of children with asthma and also those with limited physical movement. Indeed asthma has been found to be directly related to the indoor school environment (Eder, Ege and von Mutius 2006 in Blussen) Failures in these basic qualities will impact differentially on children who already find learning more challenging with a consequent effect on their performance and behaviour. This in turn will effect teacher expectations and the ways in which they interact with children. Oliveras-Ortiz et el (2017) provide a detailed review of evidence on the impact of the learning environment more generally on pupil engagement and achievement. Their own study has the advantage of asking pupils themselves, as well as teachers, who express the frustration caused through noise from other classrooms; of feeling trapped in small, poorly lit spaces, and the importance of having space to work together. We can infer that children with SEND will experience similar difficulties. Moreover, there are a number of soft measures to be considered. Shevlin et al (2008) describe the impact of classroom architecture on a young man with ataxia, on his dignity and comfort as well as his opportunity to participate in academic and social life. Visser (2001) writing about children with social emotional and behavioural difficulties, writes about the importance of classroom space allowing for flexibility in seating and about the quality of the environment giving messages about the value and expectations of the school. Attitudes and access are inextricably linked.

Two groups of children in particular have been the focus of empirical studies, children with physical difficulties, and in particular children with cerebral palsy who were the focus of a cross sectional European "SPARCLE" study, and those with autistic spectrum disorder. The use of a single medical diagnosis hides the diversity of children encompassed within these groups, but the research is useful for identifying the interactive effect of the environment on pupils' access to learning opportunities. In particular the literature on children with physical difficulties emphasizes the link between the physical environment and the attitudinal and social environment. Thus studies of children with cerebral palsy have largely concentrated on their participation in activities, and on measures of quality of life and viewed environmental factors broadly, where you live being an important factor in physical accessibility (Colver et al 2010). A study of environmental needs across 7 European countries identified that just over half the 818 children required a wheelchair and therefore wide door-ways, with a third experiencing difficulties moving around school and playground and using school facilities (Fauconnier et al (2009). Egilson \& Traustadottir (2009) collected data through survey and observation on schools in Iceland illustrating how their accessibility was compromised by the distances between areas of the school, hallways and classrooms that were cluttered. School routines such as short breaks further contributed to these navigational issues. Children who found movement, excessively effortful, and those who experience fatigue and pain were further compromised. Most participation occurred during mealtime making these physical spaces particularly important, especially given the difficulty with which students could access outside recess spaces due to the surfaces and limited structures. As we know from other research the quality of social spaces is particularly important for shaping friendships (Baker \& Donnelly 2001) as well as issues of safety given the higher incidence of bullying of children with SEND.

The growing number of children identified with ASD has led to particular interest in providing the optimal environment. There is clear recognition of children's heightened sensory sensitivity and the impact on children's behaviour and learning when they are exposed to a poor classroom environment. A review of the literature by Martin (2016) provides a detailed list of specific recommendations organised around seven themes. These reveal some contradictory views within the literature - such as whether to include withdrawal spaces or if this serves to 
isolate the child. An edited list of the commonly featured elements identified through her review are set out in table 2. These should be set within a context that the literature draws largely on interview of adults supplemented on occasions by observational data. Studies are largely small scale and have not systematically tested out the findings. Observational data varies from the anecdotal to structured studies that detail how challenging behaviours increase with noise levels (Kanakri et al 2016). Martin (2016) calls for more robust data, including the use of experimental designs rather than the rather "anecdotal" basis on which current recommendations rest.

An alternative approach to understanding an autism friendly environment was adopted by McAllister \& Sloan (2016). They provided 17 pupils with ASD in two schools with a "jigsaw" kit and an invitation for them to build a model of a school, one which, like their own, contained an ASD resource base. Seven models were built and pupils invited to discuss what they liked and disliked and what was important in designing schools. Seven aspects emerged from the analysis of this data: the positioning of the base within the wider school environment, noise and comfort, playground provision, a sense of security, internal circulation, and legibility. Key elements included; being able to choose between playgrounds with direct access from the base to an outside play area; siting the staff room and senior classes to provide security; noisy areas such as dining hall, drama and music rooms sited a distance from their base, being able to avoid unplanned and incidental difficulties such as in school corridors and stairwells and with space and time to prepare for activities, such as waiting to go into sports or dining hall; an ordering to the layout. This approach to engaging young people in developing an inclusive design lies in stark contrast to much of the research that relies on the views of others.

\begin{tabular}{|c|c|c|}
\hline Theme & Design Criteria & Specific recommendations \\
\hline \multirow[t]{9}{*}{ Space } & $\begin{array}{l}\text { Definition \& } \\
\text { Organisation }\end{array}$ & $\begin{array}{l}\text { Areas clearly defined with visible boundaries; } \\
\text { Order the space by including separate zones of different sizes }\end{array}$ \\
\hline & & Provide limited number of doors to avoid distractions \\
\hline & & $\begin{array}{l}\text { Vary ceiling height - lower to increase sense of calm, higher in } \\
\text { larger spaces for energetic activities }\end{array}$ \\
\hline & & Direct access to toilet area \\
\hline & & Controlled access to outside play area \\
\hline & $\begin{array}{l}\text { Circulation \& } \\
\text { Movement }\end{array}$ & $\begin{array}{l}\text { Circulation paths with generous space for passing, Avoid } \\
\text { narrow spaces and obstacles }\end{array}$ \\
\hline & Safety & Avoid structures that provide climbing opportunities \\
\hline & & Good sightlines for staff in classroom and playground \\
\hline & & Door hardware accessible to staff only \\
\hline \multirow[t]{6}{*}{$\begin{array}{l}\text { Sensory } \\
\text { Aspects }\end{array}$} & Sensory Escape & $\begin{array}{l}\text { Provide a withdrawal/escape space or sensory integration } \\
\text { room }\end{array}$ \\
\hline & Visual & Eliminate clutter; wall hangings that are visually distracting \\
\hline & & $\begin{array}{l}\text { Avoid pattern (e.g. brickwork), complexity in detailing; colour } \\
\text { variation }\end{array}$ \\
\hline & Auditory & Minimize noise filtering in to the classroom from outside \\
\hline & & Avoid ventilation, lighting and heating sources that hum \\
\hline & & Use acoustic tiles \\
\hline \multirow[t]{2}{*}{ Lighting } & & $\begin{array}{l}\text { Provide natural daylight - but not on learning surfaces that } \\
\text { might glare - include window coverings to control for glare }\end{array}$ \\
\hline & & $\begin{array}{l}\text { Provide lighting that can be customised e.g. dimmed with a } \\
\text { range of task lighting options }\end{array}$ \\
\hline Flexibility & & $\begin{array}{l}\text { Build in possibilities to modify environment for individual } \\
\text { needs e.g. in the type and placement of seating, in the division } \\
\text { of spaces through storage or other furnishings }\end{array}$ \\
\hline
\end{tabular}


Table 2: Design criteria for children with ASD- taken from Martin (2016)

Research with particular disabled groups raises the question of the extent to which guidance should be specific, recognising that many children will have more than one condition, and that the heterogeneity of need may mean that children with the same condition have competing needs.

\section{Guidance on School Buildings}

There has been a seed change in official school building guidance with respect to children with SEND. Early guidance was much more informative and underpinned by a clear ethos. One of the first building bulletins to address these issues, BB 94, entitled Inclusive School Design: Accommodating Pupils with Special Educational Needs and Disabilities in Mainstream Schools (Hrekow et al 2001) was based around the principle that:

“ inclusive design tries to break down unnecessary barriers and exclusions. In doing so, it will often achieve surprising and superior design solutions that will benefit everyone."p7.

The intention was to provide a safe and welcoming environment that enables "all members of the school community to enter and move around the building so that they can enjoy and participate in all aspects of school life to the best of their abilities and interests.p7" The guidance contrasts to that produced later in that it recognizes that "A number of variables make it impossible to prescribe particular design solutions" p7 which the authors see as "limiting solutions" but instead see a need for creative problem-solving with designs allowing for "choice and control" p20. Design is seen as a process, and a means to an end. The guidance takes the form of posing questions with examples of how different settings have met the challenges. The guidance is forward looking, containing sections on whole school issues and poses the likelihood that the SENCO resource base is a temporary facility as the school moves towards full inclusion.

There are important contrasts here to later government advice. BB94 was superseded by BB102 (DCSF 2008) which retained some but not all of the same messages. Entitled Designing for Disabled Children and Children with Special Educational Needs, it included guidance for both mainstream and special schools. The subject of 'Inclusive design' is not introduced until page 24 , where, perhaps a little ironically given current practices, the guidance states "inclusive school design goes beyond a one-size-fits-all model, considering all users and addressing any barriers that might deny anyone - children with SEN and disabilities, disabled staff and visitors - access to services"p24. The use of the word access is perhaps indicative that the emphasis lies with social inclusion. It is guidance with mixed messageswith repeated reference to cost efficiency and value for money. The case studies that are provided are all of specialist provision. In many ways the advice is very compatible with that of the review of Martin (2016) but with more detail both in relation to planning different areas of the school and in relation to meeting the needs of particular groups of children. The annexes include a checklist for SEN- contrasting to early statements "it is not possible to present a checklist of design changes" (Hrekow 2001 p20).

The messages in the building industry guidance are less equivocal. CABE (2008) recognizes the distinction between access and inclusion and notes that despite improvement in accessibility this has not resulted in improvements in quality. Inclusion design is therefore about dignity and respect, about being responsive to people's needs, welcoming, convenient, accommodating "without fuss" and providing choice where a single design does not solve everyone's needs. At the heart of this process lies consultation- from the very beginning of the planning process, not a built on feature. Their guidance for secondary schools (CABE 2007) states that "Many disabled children underachieve and access to education is key to their future independence. Inclusion strategies within schools should aim to ensure the full integration of all students,"p15. Reference to integration, with the connotations of children having to adapt to the school environment rather than vice versa, is replaced by inclusion in subsequent publications. Ten principles of good school design are set out. CABE guidance for the design of primary schools (CABE 2010) recognizes that inclusive schools are advantageous to all, that the needs of children with SEND should 
be considered from the outset, and that the design process should also be inclusive. It refers the reader to BB102 for more detailed design considerations. In common with other publications the influence of these works lay as much with inspiring through visual images as through the text.

Those seeking current guidance on designing inclusive schools may be surprised by the limited nature of this. BB 102 is replaced by BB104 (DfE 2015) which simply sets out to provide area guidelines for "SEND and alternative provision". Most specifically the guidance is intended for discrete provision: special schools, alternative provision, specially resourced provision and units, with only one mention of inclusion- to indicate how provision will vary according to the local policies of inclusion. No mention is made of the design process or of collaboration with stakeholders. Within the mainstream area guidelines, BB 103 (DfE 2014a), it is noted that these include "recommending reduced minimum internal and external areas" $p 3$. The guidance establishes a limit for the allocation of space : "The recommended maximum net area may be needed where there are a very high proportion of pupils with SEN or disabilities,"p7 (DfE 2014a). Further reference supports the notion of discrete needs through the provision of an SEN resource base; a SENCO office or meeting room and space for coaches or other transport for pupils with SEND. The future of new school provision appears to be excluding rather than including.

\section{Use of Guidance}

In the light of these changes to guidance, commissioners of schools may be ill prepared for their important role of contributing to an inclusive society. Amakali et al (2017) in a series of interviews with targeted employees within local authorities provides damming evidence of understanding the implementation of inclusive design. Moreover the interviews reveal a lack of ownership, as illustrated in the following comments from respondents: "inclusive design seems to be a box to tick" replied one participant, and another "not something that plays a significant part in the approval process;" and seemingly something that is forgotten "whilst inclusive design is important and access for all is essential, in planning terms it is sometimes ignored or not considered as important..". While on the one hand it is seen as part of the planning process on the other seen as something that is dealt with later by Building Control. Notably not all local authorities in this study had access specialists and where they were in post they were not seen as a source of advice. In fact policy guides were viewed as a factual source particularly with respect to any challenges that were made. It was also acknowledged that these are "very vague". At best an attitude of compliance was evident. With respect to schools, this is particularly troubling as while many elements of education are now devolved to other providers, the local authority maintains responsibility for the education of children and young people with SEND. If they have limited knowledge and understanding of inclusive designs, and don't recognize the importance of space allocation from the early planning stages, the vision of well-intentioned schools will be compromised from the outset.

\section{Process}

The design process has traditionally been seen as the exclusive domain of the professional, not least when it comes to provision for the most marginalized people in society, those who are less likely to be in the position of a client purchasing a service. This situation is exacerbated by the low profile of disabled architects (Manley \& Graft-Johnson 2013); the limited number of architectural courses in the UK with inclusive design integrated into their curriculum (Heyligen et al 2017); and the poor practices of recruitment of disabled people in the UK construction industry (Newton \& Omerod 2005). It is particularly important to gain direct access to the experiences of children with SEND. It has been argued that inclusion can only be understood by putting the child at the heart of the process and inclusive school design requires a good understanding of how people interact and experience that environment. Heylighen et al (2016) quote a Dutch architect from their research regarding how space is experienced:

It's the least understood phenomenon how space is experienced. .. Look, we make architecture with a specific [visual] image and atmosphere, that's unequivocal. For blind people, for example, this image and atmosphere probably doesn't exist, and probably there are many people with another dominant sensory experience, than the [design] pallet and compositions we acknowledge and know. [ ... ] We think about how you enter a room and it starts small and gets larger, or about routes, sightlines [ ... ] We know that very well. How that works with sounds and 
resonating sounds for somebody with a [visual] impairment we know less. I think this would interest me most, because there's relatively little knowledge." P259

In the case of children, their experience of space is clearly different from that of adults. Recent research by Pivik (2010) illustrates how disabled and non-disabled students identified more architectural barriers than the special education teacher who in turn identified more than the head teacher. Student perspectives are a vital element to understanding what makes an inclusive environment.

Fulton Suri (2007) provides three distinct approaches to considering how people influence the design process and this provides a useful framework for considering the ways in which pupils and staff are involved in the inclusive design of their school. She illustrates the many ways in which people design things for themselves, adding functionality that enables new or better uses that serve their particular needs or requirements. The framework illustrates how important it is to draw on this ability through an empowering collaborative process, that does not simply inform the design but serves to create the vision. One of the dangers in a mainstream environment is that the children who are most articulate are the ones who are asked to contribute, with dangerous assumptions that other children are less insightful. Or worse that the involvement of children is addressed as part of an accountability exercise or as Parnell and Patsarika (2011) describe in the context of Building Schools for the Future, policy rhetoric. While children are seen as users, they are not seen as a client or stakeholder. For the design process to be truly inclusive not only do meaningful ways of collecting their views or perspectives need to be employed but also a method by which these are then communicated unambiguously in a forum in which they are listened to. While this has time and cost implications, arguably it leads to more sustainable, longer lasting school designs. Parnell and Patsarki (2011) also illustrate the personal gains that can result from this learning opportunity, as children gain work related skills. As we have seen, McAllister \& Sloan (2016) through the use of their jigsaw modelling kit aptly illustrate the possibility of children with complex needs contributing to the "Design by People" processes. Tactile methods can have as much to offer as digital simulations.

\begin{tabular}{lll}
\hline Design For People & Design With People & Design by People \\
\hline $\begin{array}{l}\text { Inspired by } \\
\text { People }\end{array}$ & Learning from People & Empowering People \\
\hline Inferred needs & Translated needs & Self-recognized needs \\
The thing itself & Process and tools & Platform and vision \\
Users \& Consumers & Creators \& Designers & $\begin{array}{l}\text { Collaborators \& } \\
\text { Participants }\end{array}$ \\
\hline
\end{tabular}

Three approaches to considering how people influence the design process (adapted from Fulton Suri, 2007)

\section{Conclusion}

This chapter has raised many challenges with respect to inclusive school design. Disability is a complex phenomenon, one that can only be understood in relation to the experience of the individual and the impact on their participation in the full range of school activities. The twin drivers of inclusive design, the legal framework, with its emphasis on reasonable adjustments and processes of redress at the level of the individual, run counter to the transformative nature of inclusive schools as the vehicle to a fair and just society. These respective view points can be seen to underpin the development of generic principles of universal design versus more disability specific guidance. Arguably both positions are better than no principles or guidelines or an assumption that one size fits all. 
Although we have used the term inclusive design the principles of universal design have much to contribute. Both aim to create an environment that provides for all people and excludes no one. Choice, flexibility and control must be central features, at both a systemic and individual level. This not only demands imaginative and innovative responses to everyday problems, it also needs to be considered at every stage of the design process; as an opportunity for, rather than a limit to, creative design. Access is just the first step on the way to acquiring choice. Given the checklist approach of setting statutory minimum requirements and evidence to suggest that these are not routinely being met, then we need to consider carefully how we can foster inclusive school design in the future. Heylighen et al (2017), suggest that the focus should be shifted from issues of access to ones of spatial experience as this will be more inspirational and 'resonate' better with architects. Clearly this will need to be informed by collaboration with disabled users, thus promoting inclusive design as a process. This in turn will educate architects and lead to more extensive integration across their professional training curriculum. Schools equally have an important contribution to play here, their vision, their expertise in transforming collaboration into learning activities and a commitment to engaging the range of learners can all be brought to bear on the design process. An inclusive design may require innovative solutions to tricky issues but it will be to the benefit all children and contribute to a more equal and cohesive society.

Amakali, T. R. (2017) Inclusive design policy implementation: an organizational knowledge creation perspective. PhD thesis, University of Reading

Baker, $\mathrm{K}$ and Donnelly, M (2001) "The social experiences of children with disability and the influence of environment: a framework for intervention", Disability and Society, 16(1): 71-85

Barnes, C. (2011) Understanding Disability and the Importance of Design for All. Journal of Accessibility and Design for All, 1,1 55-80.

Barrett, P., Zhang, Y., Davies, F., \& Barrett L. (2015) Clever Classrooms. University of Salford.

CABE (2007) Creating Excellent Secondary Schools: A guide for clients http://webarchive.nationalarchives.gov.uk/20110118111850/http://www.cabe.org.uk/files/creating-excellentsecondary-schools.pdf Last accessed 18/5/18

CABE (2008) Inclusion by Design - Equality, Diversity and the Built Environment. Commission for Architecture and the Built Environment, London. www.cabe.org.uk/publications/inclusion-by-design Last accessed 18/5/18

CABE (2010) Creating Excellent primary Schools: A guide for clients https://www.designcouncil.org.uk/sites/default/files/asset/document/creating-excellent-primary-schools_2.pdf Last accessed 18/5/18

Clarkson, J., Coleman, R., (2015) History of Inclusive Design in the UK, Applied Ergonomics 46, Part B, 235-247

Clements-Croome D. (Ed) (2017) Creating the Productive Workplace. $3^{\text {rd }}$ Ed. London: Routledge

Coleman R. 1994 THE CASE FOR INCLUSIVE DESIGN - AN OVERVIEW Proceedings of the12 Triennial Congress, The International Ergonomics Association and The Human Factors Association of Canada, Toronto. http://139.91.151.66/pdf/Intro034.pdf 14/5/18

Colver, A.F. Dickinson, H.O. Parkinson, K. Arnaud, C. Beckung, E. Fauconnier, J., Marcelli, M. Mcmanus, V.,Michelsen,S.I. Parkes J., \& Thyen U. (2010) Access of children with cerebral palsy to the physical, social and attitudinal environment they need: a cross-sectional European study, Disability and Rehabilitation, 33:1,2835, DOI: 10.3109/09638288.2010.485669 
DCSF (2008) Designing for disabled children and children with special educational needs. Guidance for mainstream and special schools. BUILDING BULLETIN 102 London: DCSF

DfE (2014) Special educational needs and disability code of practice: 0 to 25 years.

https://www.gov.uk/government/publications/send-code-of-practice-0-to-25

DfE (2014a) Mainstream Schools: Area Guidelines. BB103

https://www.gov.uk/government/publications/mainstream-schools-area-guidelines. Last accessed 18/5/18

DfE (2015) SEND and alternative provision: area guidelines. Building Bulletin 104.

https://www.gov.uk/government/uploads/system/uploads/attachment data/file/485223/BB104.pf Last accessed $18 / 5 / 18$

DfE (2017) Statistics: Special Educational Needs (SEN) SFR37/July 2017

https://www.gov.uk/government/collections/statistics-special-educational-needs-sen Last accessed 18/5/18

DfEE (1997) Excellence for All Children. Meeting Special Educational Needs.

http://www.educationengland.org.uk/documents/pdfs/1997-green-paper.pdf Last accessed 18/5/18

Dyson, A. and Millward, A. (2000) Schools and special needs: issues of innovation and inclusion. London: Paul Chapman.

Eder W.E. Ege M.J. \& vov Mutius E. (2006) The asthma epidemic. New England Journal of Medicine 355 2226-2235.

Egilson S.T. \& Trausdottir R. (2009) Participation of Students With Physical Disabilities in the School Environment American Journal of Occupational Therapy, May/June 2009, 63, 264-272. doi:10.5014/ajot.63.3.264

EIDD (2004) Stockholm Declaration http://dfaeurope.eu/wp-content/uploads/2014/05/stockholmdeclaration english.pdf Last accessed 18/5/18

Fauconnier J, Dickinson HO, Beckung E, et al. (2009) Participation in life situations of 8-12 year old children with cerebral palsy: cross sectional European study BMJ 2009; 338 doi: https://doi.org/10.1136/bmj.b1458

Finkelstein .V. 2001. THE SOCIAL MODEL OF DISABILITY REPOSSESSED

http://disability-studies.leeds.ac.uk/files/library/finkelstein-soc-mod-repossessed.pdf Last accessed 18/5/18

Fulton Suri J. (2007) Include Conference http://designingwithpeople.rca.ac.uk/wp-content/uploads/Jane-Fulton-Surifor-with-by.pdf Last accessed 18/5/18

Great Britain (1978) SPECIAL EDUCATIONAL NEEDS Report of the Committee of Enquiry into the Education of Handicapped Children and Young People Chairman: Mrs H M Warnock. London: HMSO

Great Britain, (1995) Disability Discrimination Act 1995. London: HMSO

Great Britain (2010) Equality Act 2010. http://www.legislation.gov.uk/ukpga/2010/15/contents Last accessed $18 / 5 / 18$ 
Heylighen, A., Schijlen, J., Van der Linden, V., Meulenijzer D., \& Vermeersch P-W (2016) Socially innovating architectural design practice by mobilising disability experience. An exploratory study, Architectural Engineering and Design Management, 12:4, 253 265, DOI: 10.1080/17452007.2016.1172197

Heylighen, A. Van der Linden, V., \& Van Steenwinkel I. (2017) Ten questions concerning inclusive design of the built environment Building \& Environment 114 507-517.

Hopland A.O. Nyhus O.H. (2015) Does student satisfaction with school facilities affect exam results ? An empirical investigation. Facilities 33 13/14 760-774

Hrekow M., Clark H., \& Gatherhorne-Hardy F. (2001) Inclusive School Design: Accommodating Pupils with Special Educational Needs and Disabilities in Mainstream Schools. BB 94

Imms C. (2009) Children with Cerebral Palsy participate: A review of the literature. Disability and Rehabilitation, 30 24 1867-1884.

Kanakri, S.M. Shepley, M., Tassinary, L.G. Varni, J.W. Fawaz H.M. (2017) An Observational Study of Classroom Acoustical Design and Repetitive Behaviors in Children With Autism. Environment and Behaviour 49, 8, 847-873

McAllister, K. \& Sloan, S. (2016) Designed by the pupils for the pupils: an autism-friendly school British Journal of Special Education. 43, 4, 330-357.

Manley S., \& Graft-Johnson A.D. (2013) Towards Inclusion: rethinking architectural education. Construction Management and Economics 31, 8, 914-927.

Martin, C. S. (2016), Exploring the impact of the design of the physical classroom environment on young children with autism spectrum disorder (ASD). Journal of Research in Special Educational Needs, 16: 280-298.

doi:10.1111/1471-3802.12092

Newton R., \& Ormerod M 2005 Do Disabled People have a place in the UK Construction Industry? Construction Management and Economics (December 2005) 23, 1071-1081.

ODI (2017) List of Issues in Relation to the Initial Report of the United Kingdom of Great Britain and Northern Ireland Government Response. https://www.gov.uk/government/publications/disabled-peoples-rights-informationfor-the-uks-first-periodic-review/list-of-issues-in-relation-to-the-initial-report-of-the-united-kingdom-of-greatbritain-and-northern-ireland-government-response Last accessed 18/5/18

Office of Children's Commissioner (2014) It Might be Best if you Looked Elsewhere. https://www.childrenscommissioner.gov.uk/publication/it-might-be-best-if-you-looked-elsewhere/ Last accessed $18 / 5 / 18$

Oliver M (1983) Social Work with Disabled People. Basingstoke: Macmillan

Oliver, M. (1996) Understanding Disability. Basingstoke: Macmillan

Oliveras Ortiz, Yanira, (2017) The Impact of Learning Environments on Student Engagement. Educational Leadership and Policy Studies Faculty Publications and Presentations. Paper 25.

http://hdl.handle.net/10950/605 Last accessed 18/5/18

Opertti R. Walker Z., \& Zhang Y. (2014) Inclusive Education: From Targeting Groups and Schools to Achieving Quality Education as the Core of EFA. Chapter 9 in L.Florian (Edited) The Sage Handbook of Special Education. 
Ormerod, M G and Newton, R A (2005) Moving beyond accessibility: the principles of universal (inclusive) design as a dimension in nD modelling of the built environment. Architectural Engineering and Design Management, 1(2), 10310.

Ortega, L., Thompson, I. and Daniels, H. (under review) Staff Collaboration in Secondary Schools: A Social Network Analysis of Advice-Seeking Patterns regarding Support for Vulnerable Students. BERJ

Parnell R., \& Patsarika, M (2011) Young people's participation in school design: exploring diversity and power in a UK governmental policy case-study, Children's Geographies, 9:3-4, 457-475, DOI: $\underline{10.1080 / 14733285.2011 .590715}$

Pivik, J., Mccomas J., Laflamme, M. (2002) Barriers and Facilitators to Inclusive Education Exceptional Children 69, 1, 97-107

Reeve, D. (2012) Psycho-Emotional Disablism. The Missing Link ? Chapter 7 in N.Watson, A. Roulstone \& C.Thomas Routledge Handbook of Disability Studies. Abingdon: Routledge

Robinson, L.R., Leeb, R.T., Merrick, M.T. et al. (2016) Conceptualizing and Measuring Safe, Stable, Nurturing Relationships and Environments in Educational Settings Journal of Child and Family Studies 25 (5): 1488-1504.

Shakespeare, T., (2006) Disability Rights and Wrongs. London: Routledge.

Shevlin, M. , Kenny, M. and Loxley, A. (2008), A time of transition: exploring special educational provision in the Republic of Ireland. Journal of Research in Special Educational Needs, 8: 141-152. doi:10.1111/j.1471-

3802.2008.00116.x

Singh Sandhu J., \& Hendriks-Jansen H. (1976) Environmental Design for Handicapped Children. Saxon House: Farnborough

Struyve, C.,Daly, A., Vandecandelaere, M., Meredith, C., Hannes, K., and Fraine, B. (2016) More than a mentor: The role of social connectedness in early career and experienced teachers' intention to leave, Journal of Professional Capital and Community, 1, 3, pp.198-218.

The Children's Society (2015) The Good Childhood Report 2014. London: The Children's Society

UNESCO (1994) World conference on special needs education: access and quality. Paris: UNESCO.

UNESCO (2010) EFA Global Monitoring Report 2010 Reaching the Marginalized. Paris: UNESCO

United Nations Convention on the Rights of Disabled Persons (2008) Article 9:

Accessibility.https://www.un.org/development/desa/disabilities/convention-on-the-rights-of-persons-withdisabilities/article-9-accessibility.html Last accessed 18/5/18

United Nations Convention on the Rights of Disabled Persons (2008) Article 24- Education.

https://www.un.org/development/desa/disabilities/convention-on-the-rights-of-persons-with-disabilities/article-24education.html

Visser, J. (2001), Aspects of physical provision for pupils with emotional and behavioural difficulties. Support for Learning, 16: 64-68. doi:10.1111/1467-9604.00190

Wheeler A., \& Malekzadeh M. (2015) Exploring the use of new school buildings through post-occupancy evaluation and participatory action research, Architectural Engineering and Design Management,11:6, 440-

456, DOI: 10.1080/17452007.2015.1021292

Williams, J. J., Hong, S.M., Mumovic, D., \& Taylor, I. (2015) Using a unified school database to understand the effect of new school buildings on school performance in England. Intelligent Buildings International, 7:2-3, 83-100. 
World Health Organisation (2001) International classification of functioning, disability and health. (ICF) Geneva: 